CHRONIC OBSTRUCTIVE PULMONARY DISEASE

\title{
Inflammatory features of nasal mucosa in smokers with and without COPD
}

\author{
I Vachier, A M Vignola, G Chiappara, A Bruno, H Meziane, P Godard, J Bousquet, P Chanez
}

Thorax 2004;59:303-307. doi: 10.1136/thorax.2003.006650

See end of article for authors' affiliations

Correspondence to:

Dr P Chanez, Clinique des Maladies Respiratoires, Hôpital Arnaud de Villeneuve, 371 Avenue du Doyen Gaston Giraud, 34295 Montpellier Cedex 5, France; chanez@ montp.inserm.fr

Received 11 March 2003 Accepted 21 October 2003
Background: To investigate whether nasal and bronchial inflammation coexists in chronic obstructive pulmonary disease (COPD), nasal and bronchial biopsy specimens from seven control subjects, seven smokers without COPD, and 14 smokers with COPD were studied.

Methods: Nasal and bronchial biopsy specimens were taken from the same patients during bronchoscopy and squamous cell metaplasia and the thickness of the epithelium and basement membrane were measured. The numbers of eosinophils (EG2), neutrophils (elastase), macrophages (CD68), and CD8 T lymphocytes (CD8/144B) were assessed by immunohistochemistry.

Results: Smokers with and without COPD had squamous metaplasia in the nasal and bronchial epithelium. In all groups the thickness of the nasal epithelium was greater than that of the bronchial epithelium. The thickness of the basement membrane was similar in nasal and bronchial biopsy specimens from smokers with and without COPD, but was greater in the bronchi than in the nasal epithelium of controls. Eosinophil number was higher in the nasal and bronchial mucosa of smokers without COPD than in smokers with COPD or controls. Neutrophil number was higher in the nasal and bronchial mucosa of smokers with COPD than in smokers without COPD or controls. CD8 T lymphocyte numbers were similar in smokers with and without COPD and higher than in controls. There were fewer macrophages in nasal and bronchial biopsy specimens from smokers without COPD than in those with COPD.

Conclusion: Nasal and bronchial inflammation coexists in smokers and is characterised by infiltration of CD8 T lymphocytes. In smokers without COPD this feature is associated with an increased number of eosinophils, while in those with COPD it is linked to an increased number of neutrophils in both nasal and bronchial biopsy specimens.
$\mathrm{T}$ obacco smoking is one of the major causes of chronic obstructive pulmonary disease (COPD) and can induce bronchial inflammation and structural changes. Although epidemiological studies have shown a close relationship between tobacco smoking and COPD, there are few data on the possible occurrence of rhinosinusitis in patients with COPD. ${ }^{1}$ Nasal involvement is a possibility in COPD patients since tobacco smoking may induce headache and nose irritation (characterised by rhinorrhoea), nasal congestion, postnasal drip, and sneezing. ${ }^{2}$ In addition, tobacco smoke can alter mucociliary clearance ${ }^{4}$ and passive exposure to tobacco smoke has been shown to cause eosinophilic and "allergic-like" inflammation in the nasal mucosa of non-atopic children.

Although there is little evidence to suggest that COPD may involve nasal inflammation, no studies so far have been designed to address this specific issue. We have therefore tested the hypothesis that tobacco smoke might play a role not only in airway inflammation but also in nasal inflammation, and that the profile and magnitude of the inflammatory process at both sites might differ in smokers with or without COPD. It has been shown that the inflammatory process in the lower airways of smokers with COPD is characterised by structural changes of the epithelium layer as well as by increased infiltration of the airways by CD8 T lymphocytes, neutrophils, macrophages and eosinophils. ${ }^{6-8}$ We therefore investigated whether-and to what extent-these features were also present in the nasal mucosa of smokers with or without COPD.

The study was designed to evaluate markers of inflammation in nasal and bronchial mucosal biopsy specimens taken from seven smokers without COPD and 14 with COPD. We also studied nasal and bronchial biopsy specimens obtained from seven control subjects. Inflammation was evaluated by assessing the number of eosinophils (EG2), neutrophils (elastase), CD8 T lymphocytes, and macrophages (CD68) in the submucosa of nasal and bronchial biopsy tissue. In addition, the thickness of the epithelium and basement membrane was evaluated using image analysis as well as the presence of epithelial metaplasia.

\section{METHODS}

\section{Subjects}

Seven smokers with normal lung function and 14 sex and age matched smokers with COPD (forced expiratory volume in 1 second $\left(\mathrm{FEV}_{1}\right)$ range $50-70 \%$ predicted) were included in the study. They had not presented with any infections for at least 3 months.

Patients with COPD were selected according to ATS criteria and further classified using the Global Initiative for Chronic Obstructive Lung Disease (GOLD) (table 1). ${ }^{9-11}$ Patients were all current smokers with a smoking history of at least 30 pack years. They had not had any exacerbations for 2 months. None of the smokers was receiving treatment with inhaled steroids. Seven non-smoking normal healthy volunteers were also studied as a control group (table 1 ).

All patients included in the study had negative skin prick tests for all the common aeroallergens from the Montpellier area, and had no nasal symptoms. The study was approved by the local ethics committee and all patients gave written informed consent.

\section{Fibreoptic bronchoscopy}

Fibreoptic bronchoscopy was performed by the same physician as previously described. ${ }^{12}$ In each of the subjects studied nasal macroscopic scores (from 0 to 18 ) $^{12}$ and bronchial 


\begin{tabular}{|c|c|c|c|c|}
\hline & Controls $(n=7)$ & $\begin{array}{l}\text { Smokers without } \\
\text { COPD }(n=7)\end{array}$ & $\begin{array}{l}\text { Smokers with } \\
\text { COPD }(n=14)\end{array}$ & p valuet \\
\hline $\operatorname{Sex}(M / F)$ & $5 / 2$ & $7 / 0$ & $12 / 2$ & \\
\hline Age (years) & $30(24-34)$ & $52(52-58)$ & $50(44-56)$ & 0.005 \\
\hline Current smokers & 0 & $100 \%$ & $100 \%$ & $<0.0001$ \\
\hline Packs/year* & $0(0-0)$ & $40(37-56)$ & $40(40-50)$ & 0.0004 \\
\hline $\mathrm{FEV}_{1}(\%)^{*}$ & $101(100-104)$ & 95 (87-99) & $67(60-68)$ & $<0.0001$ \\
\hline $\mathrm{FEV}_{1} / \mathrm{FVC}(\%)$ & $101(92-108)$ & $100(90-102)$ & $65(58-70)$ & $<0.0001$ \\
\hline \multicolumn{5}{|l|}{ Endoscopic score } \\
\hline Nose $^{*}$ & $0(0-1)$ & $0(0-2)$ & $2(0-4)$ & 0.08 \\
\hline Bronchi* & 0 & $1(1-2)$ & $1.5(1-2)$ & 0.0001 \\
\hline
\end{tabular}

$\mathrm{FEV}_{1}=$ forced expiratory volume in 1 second; $\mathrm{FVC}=$ forced vital capacity.

*Results are expressed as medians with $25-75$ th percentiles in parentheses.

tp value for non-parametric Kruskal-Wallis test.

macroscopic scores (from 0 to 4$)^{13}$ were assessed. Four to six bronchial biopsy specimens were taken from each subject using the same forceps on a subsegmental bronchus of the lower left lobe and at the level of the inferior turbinate. Bronchial and nasal specimens were processed as previously described elsewhere. ${ }^{12}$ Briefly, biopsies were fixed in $10 \%$ formaldehyde ( $\mathrm{pH} 7.2$ ) and embedded in paraffin. Four $\mu \mathrm{m}$ tissue sections were attached to microscope slides with Lepage's glue and, after dewaxing and rehydration, the slides were analysed by immunohistochemistry. All biopsy samples were coded and sections were analysed in a blinded fashion by two independent pathologists.

\section{Epithelium thickness}

Epithelial thickness was measured in two haematoxylin/ eosin stained slides using a computerised scanning analyser allowing morphometric analysis of the epithelial surface (measured in $\mu \mathrm{m}^{2}$ ) over the entire length of the biopsy (measured in $\mu \mathrm{m}) . .^{14} 15$ The surface area was then obtained by calculating the quotient area to length.

\section{Squamous cell metaplasia}

Squamous cell metaplasia was evaluated as previously described $^{16}$ and graded as $0=$ no metaplasia, $\mathrm{l}=$ mild (metaplasia without nuclear atypia), $2=$ moderate (metaplasia with moderate atypia), and $3=$ severe (metaplasia with marked atypia).

\section{Pseudothickening of the basement membrane}

Pseudothickening of the basement membrane was measured using haematoxylin/eosin stained sections from the base of the epithelium to the outer limit of the reticular layer. At least 10 measurements at predetermined intervals were performed for each biopsy section to obtain a mean thickness for each case. ${ }^{17}$

\section{Eosinophils, neutrophils, CD8 T lymphocytes, and macrophages}

The following submucosal cells were enumerated by immunohistochemistry as previously described ${ }^{18}$ : eosinophils (EG2), neutrophils (elastase), macrophages (CD68), and CD8+ T cells (CD8/144B). ${ }^{7}$ The reaction was revealed using the alkaline phosphatase-antialkaline phosphatase (APAAP) method (Dako LSAB, Dako, Glostrup, Denmark). Control slides were treated with unrelated $\operatorname{IgG}_{2}$ mouse antibody of the same IgG isotype. Cells were evaluated in a $100 \mu \mathrm{m}$ area beneath the basement membrane in at least five higher power fields in each biopsy specimen. The results are expressed as cell number per $\mathrm{mm}^{2}$.

\section{Statistical analysis}

The results are expressed as mean, median and 25-75th percentiles. All parameters were assessed in both nasal and bronchial mucosa. Non-parametric tests were used. Within each group, comparisons between nasal and bronchial data were carried out using the Wilcoxon W test. The three groups were compared by the Kruskal-Wallis test and BonferroniDunn's post hoc tests. The nose and bronchial data were compared using the Spearman rank test.

\section{RESULTS \\ Nasal and bronchial macroscopic scores}

Compared with controls, smokers with and without COPD had abnormal bronchial macroscopic endoscopic scores $(\mathrm{p}<0.0001$ and $\mathrm{p}=0.0001$, respectively; table 1$)$. Nasal endoscopic scores did not differ significantly between controls and smokers with or without COPD.

\section{Epithelium thickness}

In smokers with or without COPD, epithelium thickness was found to be significantly greater in the nose than in the bronchi $(p=0.02$ and $p=0.03$, respectively). Epithelium thickness in controls did not differ between the nose and the bronchi.

Nasal epithelium thickness did not differ significantly between the study groups; a slight increase was seen in smokers with COPD compared with controls and smokers without COPD. The thickness of the bronchial epithelium was significantly different in the three groups, being lower (but not significantly) in smokers without COPD (table 2).

\section{Squamous cell metaplasia}

Squamous cell metaplasia was greater in the bronchi than in the nose in smokers with COPD $(p=0.008)$, but in smokers without COPD the metaplasia score was higher in the nose than in the bronchi $(\mathrm{p}=0.03)$.

Squamous cell metaplasia was observed in both the nasal and bronchial mucosa of smokers with and without COPD, but not in controls. In nasal biopsy specimens the squamous cell metaplasia score was higher in smokers without COPD than in smokers with COPD $(p=0.004)$ and controls $(p=0.0001)$. Moreover, it was also higher in smokers with COPD than in controls $(p=0.009)$. In bronchial biopsy specimens the metaplasia score was significantly higher in smokers with COPD $(p=0.004)$ than in controls (table 2$)$.

\section{Pseudothickening of the basement membrane}

In smokers with and without COPD, pseudothickening of the basement membrane was similar in the nose and in the bronchi. Neither nasal nor bronchial pseudothickening of the 
Table 2 Characteristics of the nasal and bronchial structure in the three study groups

\begin{tabular}{|c|c|c|c|c|}
\hline & Controls $(n=7)$ & $\begin{array}{l}\text { Smokers without } \\
\text { COPD }(n=7)\end{array}$ & $\begin{array}{l}\text { Smokers with COPD } \\
(n=14)\end{array}$ & p value \\
\hline \multicolumn{5}{|c|}{ Epithelial thickness ( $\mu \mathrm{m})$} \\
\hline Nose ${ }^{*}$ & $50(69)(42-100)$ & $48(54)(42-69)$ & $72(96)(58-115)$ & 0.13 \\
\hline Bronchi* & $45(55)(42-73)$ & $31(30)(26-36)$ & $53(51)(34-78)$ & 0.02 \\
\hline $\mathrm{p}$ value $\ddagger$ & 0.13 & 0.03 & 0.02 & \\
\hline \multicolumn{5}{|c|}{ Squamous cell metaplasia } \\
\hline Nose ${ }^{*}$ & $0(0)(0-0)$ & $3(2.5)(2-3)$ & $1(1)(0-2)$ & 0.0007 \\
\hline Bronchi* & $0(0)(0-0)$ & $1(1)(1-1)$ & $1.5(1.5)(0-3)$ & 0.01 \\
\hline p valueł & NS & 0.03 & 0.008 & \\
\hline \multicolumn{5}{|c|}{ Basement membrane thickness $(\mu \mathrm{m})$} \\
\hline Nose* & $5(4.5)(3-6)$ & $10(9)(4-12)$ & $7(7)(5-8)$ & 0.13 \\
\hline Bronchi* & $6(6)(5-7)$ & $7(8)(5-10)$ & $7(7)(4-9)$ & 0.74 \\
\hline $\mathrm{p}$ value $\neq$ & 0.04 & 0.86 & 0.75 & \\
\hline
\end{tabular}

basement membrane was significantly different between the three groups (table 2).

\section{Eosinophils, neutrophils, CD8 T lymphocytes, and macrophages in the submucosa}

No significant differences were seen between the nose and bronchi with respect to eosinophils, neutrophils, and CD8 T lymphocytes. Macrophage numbers were similar in the nasal and bronchial mucosa of controls; in smokers with or without COPD the number of macrophages was higher in bronchial than in nasal biopsy specimens $(\mathrm{p}=0.01$ and $\mathrm{p}=0.02$, respectively).

The number of eosinophils was higher in nasal and bronchial mucosa of smokers without COPD than in smokers with COPD ( $p=0.003$ for nose and bronchi) or in controls $(\mathrm{p}=0.0009$ and $\mathrm{p}=0.004$, respectively, in nose and bronchi; table 3$)$.

The number of neutrophils was higher in the nasal and bronchial mucosa of smokers with COPD than in smokers without COPD ( $p=0.01$ and $p=0.006$, respectively, for nose and bronchi) or in controls $(p=0.01$ and $p=0.006$, respectively; table 3 ).

The number of CD8 $\mathrm{T}$ lymphocytes was increased in smokers with or without COPD compared with controls, with a significant difference between smokers and controls ( $\mathrm{p}=0.003$ and $\mathrm{p}=0.007$, respectively, for nose and bronchi; fig 1 , table 3 ).
In nasal biopsy specimens the macrophage number did not differ between controls and smokers with COPD but it was higher than in smokers without COPD $(p=0.02$ and $p=0.007$, respectively). In bronchial biopsy specimens the macrophage number was higher in smokers with COPD than in controls and smokers without COPD $(p=0.002$ and $\mathrm{p}=0.0007$, respectively; table 3 ).

\section{DISCUSSION}

This study is the first to show that smokers with and without COPD present with nasal inflammation characterised by an increased number of CD8 $\mathrm{T}$ lymphocytes. In addition, compared with smokers with normal lung function, we have shown that smokers with COPD have nasal inflammation characterised by an increased number of neutrophils and macrophages. On the other hand, smokers without COPD showed increased eosinophilic infiltration of both the nasal and bronchial mucosa. All of these inflammatory patterns, with the exception of macrophages, were found to be similar in the nose and bronchi of smokers with and without COPD. Squamous cell metaplasia was the main structural change associated with nasal inflammation in smokers with or without COPD.

The cellular and molecular mechanisms of the inflammatory process in the airways of patients with COPD have been studied increasingly over the last decade. Several studies have recently shown a different inflammatory pattern in smokers with or without COPD. ${ }^{19}{ }^{20}$ However, so far no studies have

\begin{tabular}{|c|c|c|c|c|}
\hline & Controls ( $n=7$ ) & $\begin{array}{l}\text { Smokers without } \\
\text { COPD }(n=7)\end{array}$ & $\begin{array}{l}\text { Smokers with } \\
\text { COPD }(n=14)\end{array}$ & p valuet \\
\hline \multicolumn{5}{|l|}{ Eosinophil } \\
\hline Nose & $0(0)(0-0)$ & $10(13)(9-14)$ & $3(3)(0-6)$ & 0.0003 \\
\hline Bronchi & 0 (1) (0-0) & $7(9)(5-10)$ & 1 (1) (0-2) & 0.006 \\
\hline p valueł & NS & 0.60 & 0.11 & \\
\hline \multicolumn{5}{|l|}{ Neutrophil } \\
\hline Nose & $0(0)(0-0)$ & $0(1)(0-2)$ & $46(87)(35-165)$ & $<0.0001$ \\
\hline Bronchi & $0(0)(0-0)$ & $0(0)(0-1)$ & $48(54)(0-100)$ & 0.004 \\
\hline$p$ valueł & NS & 0.28 & 0.27 & \\
\hline \multicolumn{5}{|c|}{ CD8 T lymphocyte } \\
\hline Nose & $0(0)(0-0)$ & 19 (17) (14-24) & $3(9)(0-23)$ & 0.007 \\
\hline Bronchi & $0(0)(0-0)$ & $30(61)(21-78)$ & 17 (15) (3-24) & 0.0004 \\
\hline p valueł & NS & 0.20 & 0.23 & \\
\hline \multicolumn{5}{|c|}{ Macrophage } \\
\hline Nose & $50(51)(31-68)$ & $20(20)(6-35)$ & $45(53)(35-62)$ & 0.01 \\
\hline Bronchi & $45(46)(40-50)$ & 40 (39) (19-56) & $95(99)(61-150)$ & 0.001 \\
\hline$p$ valueł & & 0.02 & 0.01 & \\
\hline
\end{tabular}

*Results are expressed as median (mean) with 25-75th percentiles. tp value for non-parametric Kruskal-Wallis test.

$\ddagger \mathrm{p}$ value for non-parametric Wilcoxon test comparing nose and bronchi. 

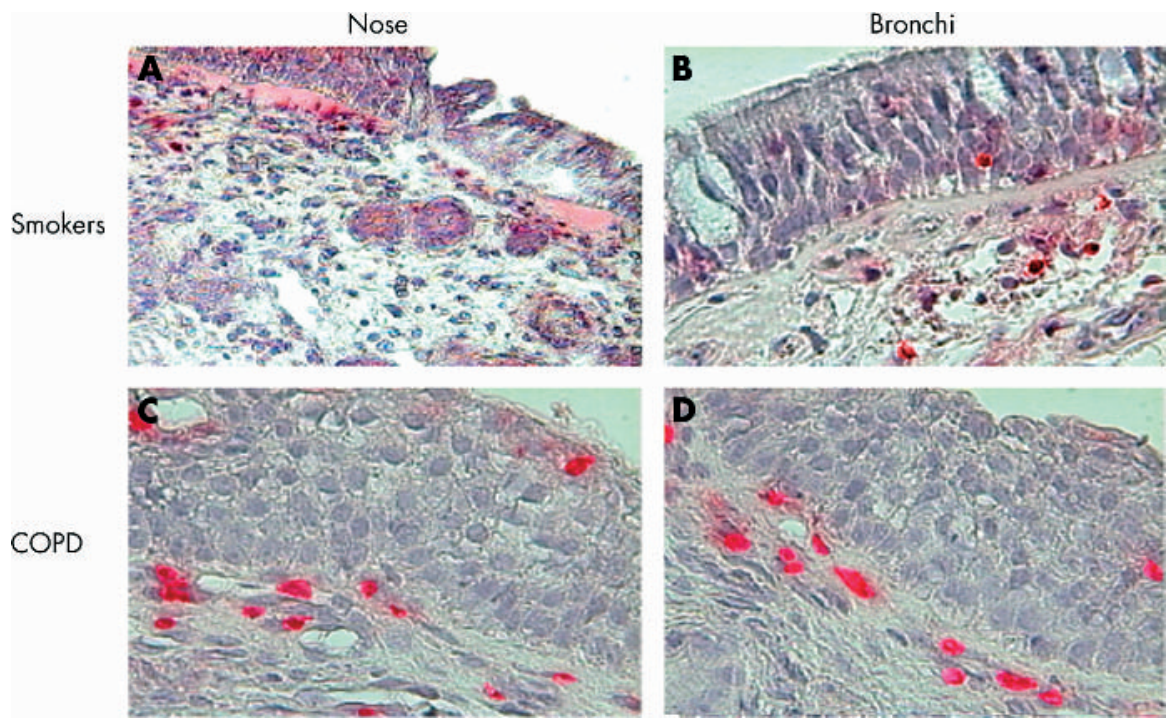

Figure 1 CD8 T lymphocyte immunoreactivity of nasal $(A, C)$ and bronchial biopsies (B, D) from smokers with (C, D) and without (A, B) COPD. In smokers with and without COPD the epithelium is not shed and CD8 immunoreactivity is high in both nasal and bronchial biopsy specimens. Original magnification $\times 400$.

examined whether bronchial and nasal inflammation coexists in smokers with or without COPD, or whether nasal mucosal inflammation patterns are similar or different in these two groups of subjects. To address these issues, we selected a group of smokers with normal lung function and a group of smokers with COPD matched for age, sex, and smoking history. The sample size of the control group and the group of smokers without COPD was lower than that of the group of smokers with COPD. We did not perform a pre-study power calculation of the sample size, so all the nonsignificant results are inconclusive and should be interpreted with caution as they may arisen as a result of type 2 error. Type 1 error is also likely as a result of the large number of statistical comparisons performed in the study (seven different comparisons), so some of the significant results made from $0.05<\mathrm{p}<0.007$ (according to the correction factor) may have arisen by chance.

Although these subjects were asymptomatic for rhinitis and did not show an abnormal nasal endoscopic score, the analysis of nasal mucosal biopsies revealed the presence of a cellular infiltrate which was rich in CD8 T lymphocytes in smokers with or without COPD. Interestingly, a similar amount of these cells was found in bronchial biopsy specimens of the same subjects, suggesting that CD8 T lymphocyte infiltration is homogeneous in upper and lower airways. $^{72}$ In addition, it appears that this is a common pattern of nasal and bronchial inflammation in smokers and is independent of COPD. By contrast, different patterns of nasal inflammation were seen in smokers with or without COPD. While eosinophilic inflammation of the nasal mucosa prevailed in the former group of subjects, COPD patients presented with an increased number of both neutrophils and macrophages. Similar to the CD8 T lymphocyte pattern, the number of neutrophils and eosinophils in nasal and bronchial mucosa did not differ in smokers with and without COPD, whereas macrophage infiltration was greater in the bronchial mucosa than in the nasal mucosa in both groups of subjects.

Taken together, these data show that nasal inflammation occurs in smokers and that the increased infiltration of CD8 T lymphocytes is a common pattern in asymptomatic smokers, with or without COPD. In addition, these results further support the role of CD8 T lymphocytes in the pathogenesis of airway mucosa inflammation associated with chronic exposure to cigarette smoke. The evidence that CD8 T lymphocytes infiltrate both nasal and bronchial mucosa extends our previous finding $s^{721}$ and suggests that these cells may also play an important role in nasal inflammation. CD8 T lymphocytes are essential effectors of the cell mediated immune response and represent the antiviral arm of the immunological system. ${ }^{22}$ These cells are able to mediate cell cytotoxicity by releasing mediators such as perforin and granzyme, ${ }^{23}$ but can also modulate the immune response by releasing cytokines such as interleukin (IL)-8 and tumour necrosis factor (TNF)- $\alpha .{ }^{24}$ It is therefore likely that CD8 T lymphocytes may be involved in the immunological response to virus infections in the nose of smokers with or without COPD. It is also possible that, following their activation, CD8 $\mathrm{T}$ lymphocytes may contribute to the recruitment of neutrophils in the nasal mucosa independently of IL-8 and TNF- $\alpha$ release. ${ }^{25}$ The presence of CD8 T lymphocytes in the nasal and bronchial mucosa may also reflect a systemic response to chronic exposure to cigarette smoke. This hypothesis is supported by the infiltration of the pulmonary vasculature in smokers without COPD. ${ }^{26}$

We also found that the profile of the cellular infiltrate in the nasal mucosa was different in smokers with normal lung function and those with COPD. The eosinophilic inflammation seen in smokers without COPD is not surprising since many studies have shown an association between smoking and eosinophilic inflammation in the blood, the nose, and the lower airways. ${ }^{57}$ This inflammatory pattern, which appears to be homogeneous in the nose and bronchi of smokers without COPD, was not found in smokers with COPD where neutrophilic inflammation predominated. The mechanisms underlying the different cellular networks in the two study groups were not investigated in this study. However, the change in the type of cells recruited in the nasal and bronchial mucosa may reflect a different inflammatory cytokine release pattern.

We also found that the inflammation of the nasal mucosa in smokers with or without COPD is associated with structural changes in the mucosa such as squamous cell metaplasia, which did not differ in the nose and bronchi of either group. This highlights a major difference from other inflammatory diseases of the airways such as asthma in 
which the structure of the epithelium differs markedly in the nose and bronchi. ${ }^{12}$ The presence of squamous cell metaplasia in the nose and bronchi of smokers with and without COPD suggests that common molecular mechanisms may underlie its pathogenesis. The enhanced ability of epithelial cells to proliferate $^{16}$ and an alteration in their differentiation pathways ${ }^{28}$ may also have an important role.

In conclusion, this study shows for the first time that nasal and bronchial inflammation coexists in smokers and is characterised by infiltration of CD8 $\mathrm{T}$ lymphocytes. In smokers with normal lung function this feature is associated with an increased number of eosinophils whereas in smokers with COPD it is associated with an increased number of neutrophils and macrophages.

\section{Authors' affiliations}

I Vachier, H Meziane, P Godard, J Bousquet, P Chanez, Clinique des Maladies Respiratoires and U-454 INSERM, Hôpital Arnaud de Villeneuve, Montpellier, France

A M Vignola, G Chiappara, A Bruno, Istituto di Fisiopatologia Respiratoria, CNR, Palermo, Italy

This study was supported by an INSERM-CNR contract and Laboratoires $3 \mathrm{M}$, France.

\section{REFERENCES}

1 Montnémery P, Svensson C, Adelroth E, et al. Prevalence of nasal symptoms and their relation to self-reported asthma and chronic bronchitis/emphysema. Eur Respir J 2001;17:596-603.

2 Benninger MS. The impact of cigarette smoking and environmental tobacco smoke on nasal and sinus disease: a review of the literature. Am J Rhinol 1999; 13:435-8.

3 Jinot J, Bayard S. Respiratory health effects of exposure to environmental tobacco smoke. Rev Environ Health 1996; 11:89-100.

4 Bascom R, Kesavanathan J, Fitzgerald TK, et al. Sidestream tobacco smoke exposure acutely alters human nasal mucociliary clearance. Environ Health Perspect 1995; 103:1026-30.

5 Vinke JG, KleinJan A, Severijnen LW, et al. Passive smoking causes an 'allergic' cell infiltrate in the nasal mucosa of non-atopic children. Int J Pediatr Otorhinolaryngol 1999;51:73-81.

6 Saetta M, Di Stefano A, Maestrelli P, et al. Activated T-lymphocytes and macrophages in bronchial mucosa of subjects with chronic bronchitis. Am Rev Respir Dis 1993; 147:301-6.

7 Saetta M, Di Stefano A, Turato G, et al. CD8+ T-lymphocytes in peripheral airways of smokers with chronic obstructive pulmonary disease. Am J Respir Crit Care Med 1998;157:822-6.

8 Saetta M, Turato G, Baraldo S, et al. Goblet cell hyperplasia and epithelial inflammation in peripheral airways of smokers with both symptoms of chronic bronchitis and chronic airflow limitation. Am J Respir Crit Care Med 2000;161:1016-21.

9 Lung function testing: selection of reference values and interpretative strategies. American Thoracic Society. Am Rev Respir Dis $1991 ; 144: 1202-18$
10 American Thoracic Society. Standards for the diagnosis and care of patients with chronic obstructive pulmonary disease (COPD) and asthma. Am Rev Respir Dis 1987; 136:225-44.

11 Pauwels RA, Buist AS, Calverley PM, et al. Global Strategy for the Diagnosis, Management, and Prevention of Chronic Obstructive Pulmonary Disease. $\mathrm{NHLBI} / \mathrm{WHO}$ global initiative for chronic obstructive lung disease (GOLD) workshop summary. Am J Respir Crit Care Med 2001; 163:1256-76.

12 Chanez $P$, Vignola A, Vic $P$, et al. Comparison between nasal and bronchial inflammation in asthmatic and control subjects. Am J Respir Crit Care Med 1999; 159:588-95

13 Van-Vyve T, Chanez P, Lacoste JY, et al. Assessment of airway inflammation in asthmatic patients by visual endoscopic scoring systems. Eur Respir J 1993;6:1116-21.

14 Vignola AM, Chiappara G, Siena L, et al. Proliferation and activation of bronchial epithelial cells in corticosteroid-dependent asthma. J Allergy Clin Immunol $2001 ; 108: 738-46$.

15 Laliberte F, Laliberte MF, Lecart S, et al. Clinical and pathologic methods to assess the long-term safety of nasal corticosteroids. French Triamcinolone Acetonide Study Group. Allergy 2000;55:718-22.

16 Demoly P, Simony-Lafontaine J, Chanez P, et al. Cell proliferation in the bronchial mucosa of asthmatics and chronic bronchitics. Am J Respir Crit Care Med 1994;150:214-7.

17 Vignola AM, Chanez P, Chiappara G, et al. Transforming growth factor-beta expression in mucosal biopsies in asthma and chronic bronchitis. Am J Respir Crit Care Med 1997; 156:591-9.

18 Vignola AM, Chanez P, Chiappara G, et al. Evaluation of apoptosis of eosinophils, macrophages, and T lymphocytes in mucosal biopsy specimens of patients with asthma and chronic bronchitis. J Allergy Clin Immunol 1999; 103:563-73.

19 Saetta M, Turato G. Airway pathology in asthma. Eur Respir J Suppl 2001;34:18s-23s.

20 Cosio Piqueras MG, Cosio MG. Disease of the airways in chronic obstructive pulmonary disease. Eur Respir J Suppl 2001;34:41s-9s.

21 O'Shaughnessy TC, Ansari TW, Barnes NC, et al. Inflammation in bronchial biopsies of subjects with chronic bronchitis: inverse relationship of CD8+ T lymphocytes with FEV1. Am J Respir Crit Care Med 1997; 155:852-7.

22 Ely K, Cauley L, Roberts A, et al. Nonspecific recruitment of memory CD8+ T cells to the lung airways during respiratory virus infections. $J$ Immunol 2003; 170: 1423-9.

23 Graubert TA, DiPersio JF, Russell JH, et al. Perforin/granzyme-dependent and independent mechanisms are both important for the development of graftversus-host disease after murine bone marrow transplantation. J Clin Invest 1997;100:904-11.

24 Kim JJ, Nottingham LK, Sin J, et al. CD8 positive T cells influence antigenspecific immune responses through the expression of chemokines. J Clin Invest 1998; 102:1112-24.

25 Klein A, Cunha FQ, Ferreira SH. The role of lymphocytes in the neutrophil migration induced by ovalbumin in immunized rats. Immunology 1995;84:577-84.

26 Peinado VI, Barbera JA, Abate $P$, et al. Inflammatory reaction in pulmonary muscular arteries of patients with mild chronic obstructive pulmonary disease. Am J Respir Crit Care Med 1999;159:1605-11.

27 Matsumoto $\mathrm{K}$, Aizawa $\mathrm{H}$, Inove $\mathrm{H}$, et al. Eosinophilic airway inflammation induced by repeated exposure to cigarette smoke. Eur Respir $J$ $1998 ; 12: 387-94$.

28 Lee JJ, Liu D, Lee JS, et al. Long-term impact of smoking on lung epithelial proliferation in current and former smokers. J Natl Cancer Inst 2001;93:1081-8. 